\title{
Contributions of PTSD polygenic risk and environmental stress to suicidality in preadolescents
}

\author{
Nikolaos P. Daskalakis ${ }^{\mathrm{a}, \mathrm{b}}$, Laura M. Schultz ${ }^{\mathrm{c}, \mathrm{d}}$, Elina Visoki ${ }^{\mathrm{d}}$, Tyler M. Moore ${ }^{\mathrm{d}, \mathrm{e}}$, \\ Stirling T. Argabright ${ }^{\mathrm{d}}$, Nathaniel G. Harnett ${ }^{\mathrm{a}}$, Grace E. DiDomenico ${ }^{\mathrm{d}}$, Varun Warrier ${ }^{\mathrm{f}}$, \\ Laura Almasy ${ }^{\mathrm{c}, \mathrm{d}, \mathrm{g}}$, Ran Barzilay ${ }^{\mathrm{d}, \mathrm{e}, \mathrm{h}, *}$

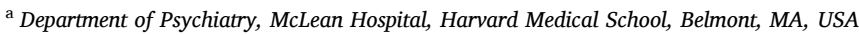 \\ ${ }^{\mathrm{b}}$ Stanley Center for Psychiatric Research, Broad Institute of MIT and Harvard, Cambridge, MA, USA \\ ${ }^{\mathrm{c}}$ Department of Biomedical and Health Informatics, Children's Hospital of Philadelphia (CHOP), Philadelphia, PA, USA \\ ${ }^{\mathrm{d}}$ Lifespan Brain Institute, CHOP and Penn Medicine, Philadelphia, PA, USA \\ ${ }^{\mathrm{e}}$ Department of Psychiatry, Perelman School of Medicine, University of Pennsylvania, Philadelphia, PA, USA \\ ${ }^{\mathrm{f}}$ Department of Psychiatry, University of Cambridge, Cambridge, United Kingdom \\ ${ }^{g}$ Department of Genetics, Perelman School of Medicine, University of Pennsylvania, Philadelphia, PA, USA \\ ${ }^{\mathrm{h}}$ Department of Child and Adolescent Psychiatry and Behavioral Sciences, CHOP, Philadelphia, PA, USA
}

\section{A R T I C L E I N F O}

\section{Keywords:}

Polygenic risk score

PTSD

Suicide

Stress

Child psychiatry

\begin{abstract}
A B S T R A C T
Suicidal ideation and attempts (i.e., suicidality) are complex behaviors driven by environmental stress, genetic susceptibility, and their interaction. Preadolescent suicidality is a major health problem with rising rates, yet its underlying biology is understudied. Here we studied effects of genetic stress susceptibility, approximated by the polygenic risk score (PRS) for post-traumatic-stress-disorder (PTSD), on preadolescent suicidality in participants from the Adolescent Brain Cognitive Development (ABCD) Study ${ }^{\circledR}$. We further evaluated PTSD-PRS effects on suicidality in the presence of environmental stressors that are established suicide risk factors. Analyses included both European and African ancestry participants using PRS calculated based on summary statistics from ancestryspecific genome-wide association studies. In European ancestry participants $(\mathrm{N}=4,619, \mathrm{n}=378$ suicidal), PTSDPRS was associated with preadolescent suicidality (odds ratio $[\mathrm{OR}]=1.12,95 \% \mathrm{CI} 1-1.25, \mathrm{p}=0.038$ ). Results in African ancestry participants $(\mathrm{N}=1,334, \mathrm{n}=130$ suicidal) showed a similar direction but were not statistically significant (OR $=1.21,95 \% \mathrm{CI} 0.93-1.57, \mathrm{p}=0.153$ ). Sensitivity analyses using non-psychiatric polygenic score for height and using cross-ancestry PTSD-PRS did not reveal any association with suicidality, supporting the specificity of the association of ancestry-specific PTSD-PRS with suicidality. Environmental stressors were robustly associated with suicidality across ancestries with moderate effect size for negative life events and family conflict (OR 1.27-1.6); and with large effect size (OR 4) for sexual-orientation discrimination. When combined with environmental factors, PTSD-PRS showed marginal additive effects in explaining variability in suicidality, with no evidence for $\mathrm{G} \times \mathrm{E}$ interaction. Results support use of cross-phenotype PRS, specifically stresssusceptibility, as a genetic marker for suicidality risk early in the lifespan.
\end{abstract}

\section{Introduction}

\subsection{Preadolescent suicidality}

Suicide is a complex behavior driven by complex environmental and genetic factors, and their interaction (Turecki and Brent, 2016). Suicide is the second leading cause of death in youth (Centers for Disease Control and Prevention, 2021), with steadily increasing rates of childhood and preadolescent suicidal ideation and suicide attempts (i.e., suicidality) particularly for Black-American youth (Bridge et al., 2018; Lindsey et al., 2019; Mishara and Stijelja, 2020; Naghavi and Global Burden of Disease Self-Harm, 2019; Plemmons et al., 2018; Ruch et al., 2019; Yu and Chen, 2019). Childhood suicidality predicts adult psychiatric morbidity and mortality and thus may represent an early marker for lifelong vulnerability to poor mental health (Copeland et al., 2017; Herba et al., 2007). Understanding risk factors of preadolescent

\footnotetext{
* Corresponding author. 10th floor, Gates Pavilion, Hospital of the University of Pennsylvania, 34th and Spruce Street, Philadelphia, PA, 19104, USA.

E-mail addresses: ran.barzilay@pennmedicine.upenn.edu, barzilayr@email.chop.edu (R. Barzilay).
} 
suicidality is critical as it can guide prevention and intervention early in the lifespan (Cash and Bridge, 2009).

\subsection{Genetics and suicidality}

Genetic risk for suicidality is understudied, with the first genome wide association studies (GWAS) emerging recently (Mullins et al., 2019; Turecki et al., 2019), with no genetic studies of youth suicidality. One potential approach to better understand the genetic underpinning of suicidal behavior is to study polygenic risk for phenotypes associated with suicide, like neuropsychiatric risk (Bigdeli et al., 2021; Laursen et al., 2017; Warrier and Baron-Cohen, 2019). In light of the mounting evidence linking environmental adversity with suicidal behavior (Fazel and Runeson, 2020; Turecki et al., 2019), other predisposition factors (such as genetic risk) that also influence stress reactivity likely also contribute to suicidal behavior. Progress has been made in the understanding of the genetic underpinnings of stress susceptibility with the latest GWAS of post-traumatic-stress-disorder (PTSD) showing significant heritability (Gelernter et al., 2019; Nievergelt et al., 2019; Stein et al., 2021) with the involved genomic loci starting to reveal diverse biological pathways in brain and non-brain tissues and cell types (Chatzinakos et al., 2020; Girgenti et al., 2021; Huckins et al., 2020). GWAS also allow for calculation of a polygenic risk score (PRS) of a trait in a separate target population not used in the GWAS (Crouch and Bodmer, 2020). The PRS of a trait is expected to not only be predictive of that trait's phenotype in the larger population, but also to be predictive of other related phenotypes (Shen et al., 2020). A major challenge in applying polygenic risk is to calculate a PRS that accounts for diversity among ancestries, with the vast majority of research excluding non-European ancestry individuals thus limiting their wider generalizability (Duncan et al., 2019; Martin et al., 2019).

\section{3. $A B C D$ Study ${ }^{\circledR}$ as a resource to study preadolescent suicidality}

Here we aimed to address the gap in studies of genetic susceptibility to early life suicidal behavior, using data from the Adolescent Brain Cognitive Development study (ABCD Study ${ }^{\circledR}$ ), which included a genotyped population of diverse US preadolescents with phenotyping of environmental adversities (Hoffman et al., 2019) and suicidality (Janiri et al., 2020). We calculated ancestry-specific PTSD-PRS for European ancestry and African ancestry participants from the ABCD Study®. We evaluated whether PTSD-PRS, as a genetic indicator of stress susceptibility, can predict preadolescent suicidality. We further evaluated whether PTSD-PRS has additive or interactive effects with early life adversities that are known risk factors associated with preadolescent suicidality. Our analytic approach was ancestry-specific, but we also meta-analyzed the two ancestries to estimate effects across ancestries. We hypothesized that (1) PTSD-PRS would be predictive of preadolescent suicidality, but with a smaller effect size than environmental adversity; and that (2) ancestry-specific PRS would outperform cross-ancestry PRS in the prediction of preadolescent suicidality.

\section{Methods}

\subsection{Participants}

The ABCD Study ${ }^{\circledR}$ sample includes a cohort of 11,878 children aged 9-10 years at baseline, primarily recruited through local school systems (Garavan et al., 2018). Participants were enrolled at 21 sites, with the catchment area encompassing over $20 \%$ of the entire US population in this age group. All participants gave informed assent. Parents/caregivers signed informed consent. The ABCD Study ${ }^{\circledR}$ protocol was approved by the University of California, San Diego Institutional Review Board (IRB), and was exempted from a full review by the University of Pennsylvania IRB.

Here we used data collected at the 1-year follow-up assessment, which included a tool that assessed self-reported experiences of adversity including negative life events and experiences of discrimination. In some cases, variables were only available from baseline assessment, either because measures were deemed non-longitudinal, or because the ABCD Study ${ }^{\circledR}$ data collection schedule did not include these items at the 1-year follow-up (see Supplementary Table S1 for details on all ABCD Study ${ }^{\circledR}$ measures used in the current analysis). We included phenotypic data from ABCD Study ${ }^{\circledR}$ data release 3.0 (https://abcdstudy.org/), while PRS were calculated using genotype data from release 2.0.1. To mitigate potential effects of family-relatedness, as ABCD Study ${ }^{\circledR}$ included twins and other related individuals, we only included one participant per family (the oldest). The final sample analyzed here included participants from European ancestry (EUR, $\mathrm{N}=4619$ ) and from African ancestry (AFR, $N=1334$ ), based on inferred genetic ancestry rather than on parental reports of race (detailed below).

\subsection{Calculation of ancestry-specific PTSD-PRS}

PRS are commonly computed using summary statistics from GWAS of independent population(s) from the same ancestry group. Since the vast majority of GWAS have been run only for EUR samples, computing PRS for non-EUR samples often forces researchers to rely on EUR GWAS, with limited evidence to support this approach (Duncan et al., 2019; Martin et al., 2019). Using GWAS summary statistics from the Psychiatric Genomics Consortium-Posttraumatic Stress Disorder Group (PGC-PTSD) that were computed separately for EUR ( $\mathrm{N}=23,212$ cases and 151,447 controls) and AFR $(\mathrm{N}=4363$ cases and 10,976 controls) (Nievergelt et al., 2019), we calculated ancestry specific PTSD-PRS for EUR and AFR participants of the ABCD Study ${ }^{\circledR}$, as described below.

Participants from the ABCD Study ${ }^{\circledR}$ provided biospecimens (Uban et al., 2018), and genotype data were obtained from NDA (\#2573, fix release 2.0.1). Prior to imputation, PLINK 1.9 (Chang et al., 2015) was used to remove single nucleotide polymorphisms (SNPs) with $>5 \%$ missingness, samples with more than $10 \%$ missingness, and samples in which genotyped sex was different from reported sex. Genotypes were phased (Eagle v.2.4) and imputed to the 1000 Genomes Project Other/Mixed GRCh37/hg19 reference panel (Phase 3 v.5) using Minimac 4 via the Michigan Imputation Server (Das et al., 2016). Following imputation, only polymorphic sites with imputation quality $R^{2} \geq 0.7$ and MAF $\geq 0.01$ were retained.

Multi-dimensional scaling (MDS) of the imputed genotypes was conducted using KING v.2.2.4 (Manichaikul et al., 2010) to identify the top ten ancestry principal components (PCs) for each study participant. These PCs were projected onto the 1000 Genomes Project PC space, and genetic ancestry was inferred using the e1071 (Meyer et al., 2020) support vector machines package in $R$ ( $R$ Core Team, 2019) (Supplementary Fig. S1). Based on these inferences, AFR and EUR cohorts were established for the ABCD Study ${ }^{\circledR}$ dataset; all other ancestry groups were excluded from further analysis. A second round of unprojected MDS was then performed within the EUR and AFR groups to produce ten PCs that were regressed out of the standardized PRS to adjust for genetic ancestry (Supplementary Figs. S2-S3). KING was also used to identify all pairwise relationships out to third degree relatives based on estimated kinship coefficients and inferred IBD segments.

PRS-CS (PRS using SNP effect sizes under continuous shrinkage) (Ge et al., 2019) was used to infer posterior effect sizes of the SNPs in the dataset that overlapped with the PGC-PTSD GWAS summary statistics and an external 1000 Genomes linkage disequilibrium (LD) panel matched to the ancestry group used for the GWAS. PRS for the EUR and AFR subsets of the ABCD Study ${ }^{\circledR}$ participants were computed twice, once using the EUR LD panel and EUR GWAS and once using the AFR LD panel and AFR GWAS. Raw PRS were produced by PLINK 1.9 and then standardized and ancestry-corrected in R. 


\subsection{Phenotypic measures}

\subsubsection{Exposures}

The ABCD Study ${ }^{\circledR}$ assessment included multiple instruments that tapped adversity. For the current analysis, we specifically chose measures that had been previously linked to increased suicide risk in youth: negative life events (a continuous count of events judged as "bad" by the study's participants, measure ple_y_ss_total_bad) (Serafini et al., 2015); family conflict (child-reported sub-scale from the Family Environment Scale, measure fes02fes_y_ss_fc) (Janiri et al., 2020); and discrimination against lesbian, gay, or bisexual, (LGB) individuals (past 12-months, binary variable, measure dim_yesno_q3) (Almeida et al., 2009).

\subsubsection{Outcome measures}

The ABCD Study ${ }^{\circledR}$ included the Kiddie-Structured Assessment for Affective Disorders and Schizophrenia for DSM-5 (KSADS-5) (Kaufman et al., 1997) that assessed past or current suicidal ideation and attempt (Janiri et al., 2020). Items relating to self-injurious behavior without suicidal intent were not included. As the proportion of suicidal attempts was low, and to avoid multiple testing to mitigate risk of type I error, we grouped together suicidal ideation and attempt, in line with previous analyses (Janiri et al., 2020). Thus, suicidal outcomes were collapsed into a single binary measure termed suicidality. Rates of suicidal ideation and suicidal attempts are presented in Supplementary Table S2.

\subsection{Statistical analyses}

We used the SPSS 26.0 statistical package and R 3.6.1 for our data analysis. Mean (standard deviation [SD]) and frequency (\%) were reported for descriptive purposes. Univariate comparisons were made using t-tests for continuous measures and chi-square tests for categorical variables. We employed listwise deletion for participants with missing data. Rates of missing values for all variables included in the current study were lower than $1.7 \%$, with the exception of LGB discrimination that was missing in 5.1\% in European Ancestry and 7.4\% in the African Ancestry participants. We used two-tailed tests for all models. Data analyses were conducted between January and February 2021. Data preprocessing and analyses are detailed at https://github.com/bar zilab1/abcd_discrimination.

\subsubsection{Main analysis}

To determine the association of PTSD-PRS with preadolescent suicidality, we conducted a binary logistic regression model with the PTSDPRS (residualized using 10 ancestry PCs) as the independent variable and suicidality (binary) as the dependent variable, co-varying for age and sex. To allow ancestry specificity, we used a PRS computed in a EUR GWAS training set for the EUR participants, and a PRS computed in an AFR GWAS training set for the AFR participants. We visualized the association between PTSD-PRS in both ancestries in both sexes across PRS quintiles (Fig. 1). To estimate the effect of PRS in the AFR and EUR

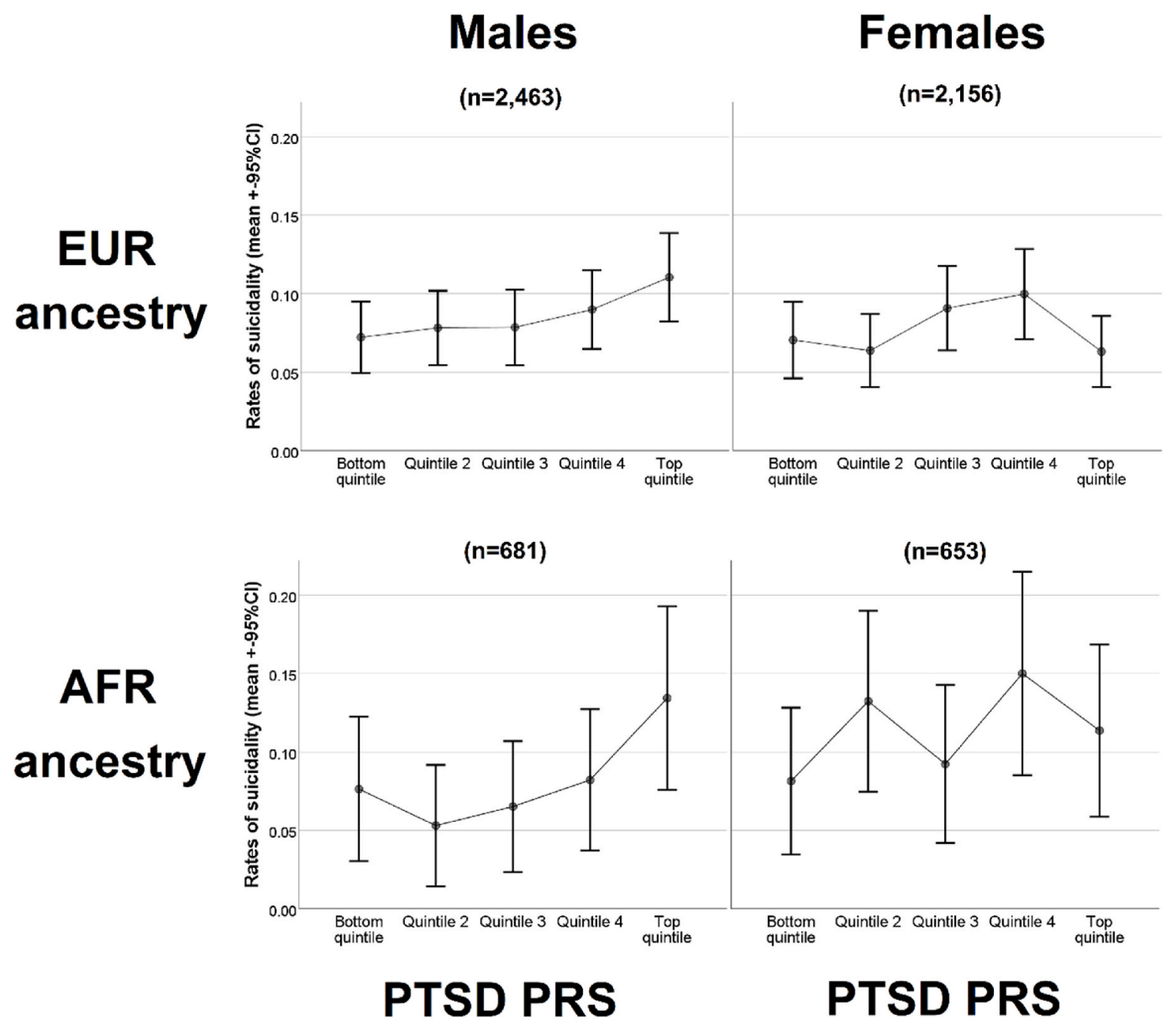

Fig. 1. Visual representation of ancestry-specific PTSD-PRS and childhood suicidality by ancestry and sex.

Abbreviations: EUR = European ancestry; AFR = African Ancestry; PTSD = post-traumatic stress disorder; PRS = polygenic risk score. 
samples combined, we conducted fixed effect inverse-variance metaanalyses using the ancestry specific PRS, using the following formula: $w_{i}=\frac{1}{S E_{i}^{2}} ; S E_{\text {meta }}=\sqrt{1 / \Sigma_{i} w_{i}} ;$ Beta $_{\text {meta }}=\Sigma_{i} \beta_{i} w_{i} / \Sigma_{i} w_{i}$, where $\beta_{i}$ is the standardized regression coefficient of the PRS for the two ancestry groups (denoted by $i$ ), $S E_{i}$ is the associated standard error, and $w_{i}$ is the weight. P-values were calculated from Z scores $\left(\right.$ Beta $\left.a_{\text {meta }} / S E_{\text {meta }}\right)$. We report Nagelkerke's $\mathrm{R}^{2}$ for each ancestry separately but not for the metaanalyzed results as there is currently no consensus about the best method to calculate this.

To estimate environmental adversities' effects in participants from each ancestry (EUR and AFR), we conducted a single binary logistic regression model with the three environmental adversities (negative life events, family conflict, and LGB discrimination) as the independent variables and suicidality (binary) as the dependent variable, co-varying for age and sex. Additionally, we conducted fixed effect inverse-variance weighted meta-analysis of the EUR and AFR samples combined for each of the three environmental adversities.

To estimate whether PTSD-PRS can additively explain variability in suicidality over and above environmental adversities, we used a stepwise approach. We first ran binary logistic regression models with each of the environmental adversities as the independent variables (three separate models for each of the three environmental adversities), and suicidality as the dependent variable (Step 1). Thereafter, we added the PTSD-PRS (Step 2) to evaluate whether the model explains more variability (i.e., increase in the R-square). Thereafter, we tested whether there is evidence for $\mathrm{GX} \mathrm{E}$ through the introduction of the environmental adversity X PTSD-PRS product (Step 3). This stepwise approach was done separately for each of the three environmental adversities (and not in a single model), to allow maximal chance of PTSD-PRS to explain variability. For steps 1 and 2, we conducted fixed effect inverse-variance weighted meta-analysis of the EUR and AFR samples combined for each of the three environmental adversities. Lastly, we tested whether the PTSD-PRS can the additively explain variability in suicidality over and above the three environmental adversities combined in a single model.

\subsubsection{Sensitivity analyses}

To test the specificity of the ancestry-specific PTSD-PRS to suicidality we ran two models where we substituted the ancestry-specific PTSDPRS. In the first model, we included an ancestry-specific polygenic score for a non-related phenotype, height PRS (using a diverse training set that allowed calculation of EUR and AFR PRS (Marouli et al., 2017)). This model allowed us to test whether the PTSD-PRS is specific to the psychiatric phenotype. In the second model, we included the cross-ancestry PTSD-PRS, so that in EUR participants we used the AFR derived PTSD-PRS, and in the AFR participants we used the EUR derived PTSD-PRS. This allowed us to test whether the ancestry specificity is important when testing the association between PTSD-PRS and suicidality and to assess whether PTSD-PRS calculated using the larger, more powerful EUR PTSD GWAS had the potential to explain more variance in the AFR sample than PTSD-PRS from a smaller, but ancestry-matched, GWAS.

\section{Results}

\subsection{Comparison between participants with and without suicidality}

Comparison of demographics, PTSD-PRS and experiences of environmental adversities between Suicidal and Non-suicidal participants is described in Table 1. Participants who endorsed suicidality comprised $8.2 \%$ of the EUR participants and $9.7 \%$ of the AFR participants. Univariate comparison did not reveal significant age or sex differences. As expected, participants who endorsed suicidality had more experiences of all three environmental adversities, in both ancestries (all p's $<0.001$ ).

\subsection{Association of ancestry-specific PTSD-PRS and suicidality}

In EUR participants, a PTSD-PRS calculated from a EUR GWAS (i.e., ancestry-specific) was significantly associated with suicidality with a modest effect size (odds ratio $[\mathrm{OR}]=1.12,95 \% \mathrm{CI}=1.01-1.25, \mathrm{p}=$ 0.038), with Nagelkerke $R^{2}=0.003$. In AFR participants, the AFR PTSDPRS was not significantly associated with suicidality, but a similar direction of effect was observed (OR $=1.21,95 \%$ CI 0.93-1.57, $\mathrm{p}=0.153$ ), with Nagelkerke $R^{2}=0.010$. No differences in the height polygenic scores were observed between suicidal and non-suicidal participants in both ancestries.

Furthermore, meta-analysis of the AFR and EUR samples identified significant effects $(\mathrm{OR}=1.14,95 \% \mathrm{CI} 1.03-1.26, \mathrm{p}=0.014)$. Table 2 details full model statistics for both ancestries. Fig. 1 presents a visual presentation of the relationship between PTSD-PRS and suicidality in

Table 2

Ancestry specific PTSD-PRS' association with childhood suicidality.

\begin{tabular}{lllllll}
\hline Sample & PTSD-PRS & B & SE & OR & $95 \%$ CI & $\begin{array}{l}\mathrm{p}- \\
\text { value }\end{array}$ \\
\hline EUR sample & $\begin{array}{l}\text { EUR } \\
\text { derived }\end{array}$ & 0.116 & 0.056 & 1.123 & $1.006-1.253$ & 0.038 \\
AFR sample & $\begin{array}{l}\text { AFR } \\
\text { derived }\end{array}$ & 0.19 & 0.133 & 1.209 & $0.932-1.569$ & 0.153 \\
$\begin{array}{c}\text { Meta-analysis } \\
\text { of EUR and } \\
\text { AFR }\end{array}$ & $\begin{array}{l}\text { Ancestry } \\
\text { specific }\end{array}$ & 0.12 & 0.051 & 1.135 & $1.026-1.256$ & 0.014 \\
\hline
\end{tabular}

Abbreviations: PTSD $=$ post-traumatic stress disorder; PRS $=$ polygenic risk score; EUR $=$ European ancestry; AFR $=$ African ancestry; $\mathrm{SE}=$ standard error; $\mathrm{OR}=$ odds ratio; $\mathrm{CI}=$ confidence interval.

Table 1

Sample characteristics.

\begin{tabular}{|c|c|c|c|c|c|c|c|c|c|c|c|}
\hline & & \multicolumn{5}{|c|}{ EUR sample $(\mathrm{N}=4619)$} & \multicolumn{5}{|c|}{ AFR sample $(\mathrm{N}=1334)$} \\
\hline & & \multicolumn{2}{|c|}{$\begin{array}{l}\text { No suicidality }(\mathrm{n}= \\
4241)\end{array}$} & \multicolumn{2}{|c|}{$\begin{array}{l}\text { Suicidality }(\mathrm{n}= \\
378)\end{array}$} & \multirow[b]{2}{*}{$\begin{array}{l}\mathrm{p}- \\
\text { value }\end{array}$} & \multicolumn{2}{|c|}{$\begin{array}{l}\text { No suicidality }(\mathrm{n}= \\
1204)\end{array}$} & \multicolumn{2}{|c|}{$\begin{array}{l}\text { Suicidality }(\mathrm{n}= \\
130)\end{array}$} & \multirow[b]{2}{*}{$\begin{array}{l}\mathrm{p}- \\
\text { value }\end{array}$} \\
\hline & & $\begin{array}{l}\text { Mean/ } \\
\mathrm{n}\end{array}$ & $\mathrm{SD} / \%$ & $\begin{array}{l}\text { Mean/ } \\
\mathrm{n}\end{array}$ & $\mathrm{SD} / \%$ & & $\begin{array}{l}\text { Mean/ } \\
\mathrm{n}\end{array}$ & $\mathrm{SD} / \%$ & $\begin{array}{l}\text { Mean/ } \\
\mathrm{n}\end{array}$ & $\mathrm{SD} / \%$ & \\
\hline \multirow[t]{3}{*}{ Demographics } & Age years, mean (SD) & 10.99 & 0.63 & 11 & 0.65 & 0.61 & 10.95 & 0.63 & 11 & 0.58 & 0.362 \\
\hline & Sex male, n (\%) & 2252 & $53.10 \%$ & 211 & $55.80 \%$ & 0.31 & 625 & $51.90 \%$ & 56 & $43.10 \%$ & 0.056 \\
\hline & Sex female, n (\%) & 1989 & $46.90 \%$ & 167 & $44.20 \%$ & 0.31 & 579 & $48.10 \%$ & 74 & $56.90 \%$ & 0.056 \\
\hline \multirow[t]{3}{*}{ Environmental adversities } & $\begin{array}{l}\text { Negative life events count, } \\
\text { mean (SD) }\end{array}$ & 2.09 & 1.97 & 3.48 & 2.69 & $<.001$ & 3.05 & 2.61 & 4.92 & 2.92 & $<.001$ \\
\hline & $\begin{array}{l}\text { Family conflict scale, mean } \\
\text { (SD) }\end{array}$ & 1.64 & 1.77 & 2.8 & 2.12 & $<.001$ & 2.12 & 1.83 & 2.85 & 2.1 & $<.001$ \\
\hline & LGB discrimination, n (\%) & 107 & $2.52 \%$ & 52 & $13.76 \%$ & $<.001$ & 53 & $4.40 \%$ & 22 & $16.92 \%$ & $<.001$ \\
\hline
\end{tabular}

Abbreviations: EUR = European ancestry; AFR = African ancestry; SD = standard deviation; PTSD = post-traumatic stress disorder; LGB = Lesbian, gay, bisexual. 
both ancestries and both sexes.

We then conducted a sensitivity analysis to assess specificity of the finding of a significant association of the ancestry-specific PTSD-PRS with suicidality in the EUR participants (Supplementary Table S3). Substitution of the PTSD-PRS with a PRS for non-psychiatric phenotype (polygenic score for height) was not associated with suicidality; nor was a cross-ancestry PTSD-PRS derived from an AFR population.

\subsection{Environmental adversity and suicidality}

In both ancestries, environmental adversities were significantly associated with suicidality with small-to-moderate effect size for negative life events and family conflict (OR ranging from 1.27 to 1.6 in EUR, AFR, and EUR/AFR meta-analytic samples); and with large effect size ( $\mathrm{OR} \sim 4.0$ in EUR, AFR, and EUR/AFR meta-analytic samples) for LGB discrimination (Table 3).

\subsection{Integrating PTSD polygenic risk into environmental models of suicidality}

First, to evaluate the potential additive contribution of PTSD-PRS in explaining variability in suicidality over and above environmental adversity, we tested its addition to three individual environmental adversities in three separate models. The addition of PTSD-PRS made a small additive contribution to each model including the one of the adversity measures (negative life events, family conflict, or LGB discrimination), in both EUR and AFR samples (Table 4). While the addition of PTSD-PRS effects was not significant in any of the three adversity models in each of either EUR or AFR ancestry-specific analyses separately, meta-analyses of the EUR and AFR samples identified a significant effect of PTSD-PRS after accounting for negative life events and family conflict, but not LGB discrimination (Table 4). No evidence for G X E were observed (for each adversity X PTSD-PRS, p's > 0.38).

Lastly, to further evaluate the potential utility of PTSD-PRS to add to the variance explained by environmental adversities, we ran models that included all three environmental adversities and then added the PTSDPRS (Table 5). The results of this model suggest that in AFR, the addition of the PRS adds to the variance explained compared to the model relying on the three environmental adversities (Nagelkerke R2 is 0.119 in model with PRS and 0.116 in model without PRS). In the EUR sample, the addition of PTSD PRS does not add to the variance explained (Nagelkerke R2 remained 0.133 when adding the PTSD-PRS).

\section{Discussion}

\subsection{Broad context}

In this study, we investigated the effects of stress-related genetic factors and stress exposures in relation to the development of preadolescent suicidality. We linked PRS of stress susceptibility (i.e., PRS of PTSD) with preadolescent suicidality, indicating a genetic overlap in this young population that has so far received limited attention in the context of genetic risk for suicidal ideation or attempts. Our findings add to the existing literature in adult populations linking other psychiatric PRS (for depression, schizophrenia and autism) to suicidal behavior (Bigdeli et al., 2021; Laursen et al., 2017; Warrier and Baron-Cohen, 2019). Although causal analysis need to be conducted, the observed influence of both environmental stressors and genetic stress-susceptibility on suicidality so early in the lifespan suggests that early life stress biology mechanisms are putative drivers of adulthood suicidal behavior and might be potential targets of suicide prevention approaches.

Our findings are important for several reasons. First, we show for the first time that a genetic marker of stress susceptibility derived from an adult psychiatric trait GWAS is associated with a clinical psychiatric phenotype in preadolescents. Notably, rate of preadolescent suicidality is showing an alarming rise (Ruch et al., 2019), and its genetic correlates are understudied. Second, we show that a PRS derived from a psychiatric disorder that is not suicide is relevant in explaining variability in suicidality even after accounting for environmental stressors, supporting the notion of using PRS across clinical phenotypes. In light of limited evidence on PRS of suicidal behavior, the current study supports further investigation into a cross-phenotype approach. Third, a key part of this analysis is the inclusion of AFR individuals in our PRS analyses. Although adversities are common across diverse populations and pose risk to the development for developing psychopathology, Black individuals face disproportionate exposure to adverse life events that contribute to such psychopathology (Slopen et al., 2016). Yet, psychiatric genetic research is skewed toward European ancestry groups (Duncan et al., 2019; Martin et al., 2019) which limits the generalizability of translational research towards the larger population. Our ancestry-specific design is especially important in light of recent epidemiological data showing that suicide rates in African American youth are disproportionately rising (Bridge et al., 2018; Price and Khubchandani, 2019), highlighting the critical need to study suicide in this population. Further inclusion of racial minorities in psychiatric genomic studies in the context of G X E is therefore critical for accurate understanding of stress biological mechanisms that lead to mental health dysfunction and the identification of PRS for prediction of psychopathology.

Suicide risk is modeled in a conceptual framework building on distal/predisposing risk, chronic environmental risk factors like lack of social cohesion and access to means, and proximal/precipitating factors, all leading to suicidal outcome (Turecki and Brent, 2016). This framework can be linked to the 3-hit hypothesis of stress-related developmental psychopathology, where a combination of genetic risk (hit-1) and early life stress (hit-2) can contribute to the expression of maladaptive behaviors after additional stress later in the lifespan (hit-3). This 3-hit hypothesis was originally coined as an interpretation of 55 years (1957-2012) of rodent and non-human primate literature of developmental programming by stress, and was supported by recent large scale cohorts (Daskalakis et al., 2013). In the current study, we leveraged the deep phenotyping of the ABCD Study and the genotyped sample to (1) model preadolescent suicidality along this framework, and

Table 3

Associations of environmental adversities with childhood suicidality.

\begin{tabular}{|c|c|c|c|c|c|c|}
\hline Sample & Environmental stressor & B & SE & OR & $95 \% \mathrm{CI}$ & $\mathrm{p}$-value \\
\hline \multirow[t]{3}{*}{ EUR sample } & Negative life events (z-score) & 0.381 & 0.049 & 1.464 & $1.33-1.611$ & $<.001$ \\
\hline & Family conflict (z-score) & 0.451 & 0.051 & 1.57 & $1.421-1.736$ & $<.001$ \\
\hline & LGB discrimination (past year, binary) & 1.383 & 0.197 & 3.988 & $2.713-5.862$ & $<.001$ \\
\hline \multirow[t]{3}{*}{ AFR sample } & Negative life events (z-score) & 0.469 & 0.089 & 1.598 & $1.341-1.904$ & $<.001$ \\
\hline & Family conflict (z-score) & 0.236 & 0.098 & 1.267 & $1.045-1.535$ & 0.016 \\
\hline & LGB discrimination (past year, binary) & 1.399 & 0.289 & 4.051 & $2.3-7.134$ & $<.001$ \\
\hline \multirow[t]{3}{*}{ Meta-analysis of EUR and AFR } & Negative life events (z-score) & 0.401 & 0.042 & 1.494 & $1.373-1.625$ & $<.001$ \\
\hline & Family conflict (z-score) & 0.405 & 0.045 & 1.449 & $1.372-1.638$ & $<.001$ \\
\hline & LGB discrimination (past year, binary) & 1.388 & 0.162 & 4.006 & $2.912-5.512$ & $<.001$ \\
\hline
\end{tabular}

Abbreviations: SE = standard error; OR = odds ratio; CI = confidence interval; EUR = European ancestry; AFR = African Ancestry; LGB = Lesbian, gay, bisexual. 
Table 4

Additive effects of PTSD-PRS in explaining childhood suicidality using specific environmental adversities individually.

\begin{tabular}{|c|c|c|c|c|c|c|c|c|c|}
\hline \multicolumn{10}{|l|}{ EUR participants $(\mathrm{N}=4619)$} \\
\hline & \multicolumn{3}{|c|}{ Model 1 (E effect) } & \multicolumn{3}{|c|}{ Model 2 (E effect + PTSD-PRS (G)) } & \multicolumn{3}{|c|}{ Model 3 (E + G + G X E) } \\
\hline & OR & $95 \% \mathrm{CI}$ & $\mathrm{p}$ & OR & $95 \% \mathrm{CI}$ & $\mathrm{p}$ & OR & $95 \% \mathrm{CI}$ & $\mathrm{p}$ \\
\hline Negative life events (z) & 1.64 & $1.51-1.79$ & $<.001$ & 1.64 & $1.501-1.78$ & $<.001$ & 1.64 & $1.51-1.79$ & $<.001$ \\
\hline PTSD-PRS & & & & 1.1 & $0.99-1.23$ & 0.091 & 1.14 & $0.96-1.35$ & 0.139 \\
\hline G X E & & & & & & & 0.99 & $0.95-1.03$ & 0.609 \\
\hline Nagelkerke $\mathrm{R}^{2}$ & 0.061 & & & 0.063 & & & 0.063 & & \\
\hline Family conflict (z) & 1.67 & $1.53-1.82$ & $<.001$ & 1.67 & $1.53-1.82$ & $<.001$ & 1.66 & $1.52-1.82$ & $<.001$ \\
\hline PTSD-PRS & & & & 1.12 & $1-1.25$ & 0.055 & 1.07 & $0.9-1.27$ & 0.462 \\
\hline G X E & & & & & & & 1.02 & $0.97-1.07$ & 0.531 \\
\hline Nagelkerke $\mathrm{R}^{2}$ & 0.059 & & & 0.061 & & & 0.061 & & \\
\hline LGB discrimination (binary) & 6.97 & $4.71-9.53$ & $<.001$ & 6.66 & $4.68-9.48$ & $<.001$ & 6.74 & $4.74-9.6$ & $<.001$ \\
\hline PTSD-PRS & & & & 1.09 & $0.97-1.22$ & 0.156 & 1.11 & $0.98-1.26$ & 0.102 \\
\hline G X E & & & & & & & 0.85 & $0.59-1.22$ & 0.383 \\
\hline Nagelkerke $\mathrm{R}^{2}$ & 0.048 & & & 0.049 & & & 0.049 & & \\
\hline \multicolumn{10}{|l|}{ AFR participants $(\mathrm{N}=1334)$} \\
\hline & \multicolumn{3}{|c|}{ Model 1 (E effect) } & \multicolumn{3}{|c|}{ Model 2 (E effect + PTSD-PRS (G)) } & \multicolumn{3}{|c|}{ Model 3 (E, G + G X E) } \\
\hline & OR & $95 \% \mathrm{CI}$ & $\mathrm{p}$ & OR & $95 \% \mathrm{CI}$ & $\mathrm{p}$ & OR & $95 \% \mathrm{CI}$ & $\mathrm{p}$ \\
\hline Negative life events (z) & 1.67 & $1.42-1.96$ & $<.001$ & 1.67 & $1.42-1.96$ & $<.001$ & 1.66 & $1.42-1.96$ & $<.001$ \\
\hline PTSD-PRS & & & & 1.2 & $0.92-1.57$ & 0.178 & 0.87 & $0.54-1.39$ & 0.558 \\
\hline G X E & & & & & & & 1.08 & $0.99-1.18$ & 0.101 \\
\hline Nagelkerke $\mathrm{R}^{2}$ & 0.065 & & & 0.068 & & & 0.072 & & \\
\hline Family conflict (z) & 1.45 & $1.23-1.71$ & $<.001$ & 1.45 & $1.23-1.71$ & $<.001$ & 1.45 & $1.22-1.71$ & $<.001$ \\
\hline PTSD-PRS & & & & 1.21 & $0.93-1.67$ & 0.158 & 1.19 & $0.77-1.83$ & 0.433 \\
\hline G X E & & & & & & & 1.01 & $0.89-1.14$ & 0.927 \\
\hline Nagelkerke $\mathrm{R}^{2}$ & 0.036 & & & 0.039 & & & 0.039 & & \\
\hline LGB discrimination (binary) & 4.84 & $2.8-8.34$ & $<.001$ & 4.87 & $2.82-8.41$ & $<.001$ & 4.83 & $2.79-8.37$ & $<.001$ \\
\hline PTSD-PRS & & & & 1.23 & $0.93-1.64$ & 0.145 & 1.2 & $0.89-1.64$ & 0.236 \\
\hline G X E & & & & & & & 1.18 & $0.53-2.64$ & 0.68 \\
\hline Nagelkerke $\mathrm{R}^{2}$ & 0.054 & & & 0.058 & & & 0.058 & & \\
\hline \multicolumn{10}{|c|}{ Meta-analysis of EUR and AFR ( $\mathrm{N}=5953)$} \\
\hline & \multicolumn{3}{|c|}{ Model 1 (E effect) } & \multicolumn{3}{|c|}{ Model 2 (E effect + PTSD-PRS (G)) } & & & \\
\hline & OR & $95 \% \mathrm{CI}$ & $\mathrm{p}$ & OR & $95 \% \mathrm{CI}$ & $\mathrm{p}$ & & & \\
\hline Negative life events (z) & 1.647 & $1.53-1.78$ & $<.001$ & 1.642 & $1.524-1.769$ & $<.001$ & & & \\
\hline PTSD-PRS & & & & 1.115 & $1.006-1.236$ & 0.038 & & & \\
\hline Family conflict (z) & 1.616 & $1.52-1.78$ & $<.001$ & 1.614 & $1.491-1.747$ & $<.001$ & & & \\
\hline PTSD-PRS & & & & 1.128 & $1.073-1.186$ & 0.021 & & & \\
\hline LGB discrimination (binary) & 6.084 & $4.53-8.18$ & $<.001$ & 6.073 & $4.516-8.169$ & $<.001$ & & & \\
\hline PTSD-PRS & & & & 1.109 & $1.051-1.169$ & 0.061 & & & \\
\hline
\end{tabular}

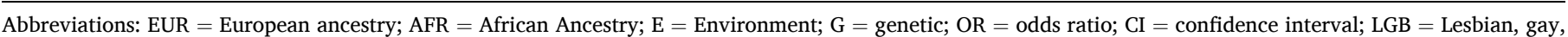
bisexual.

(2) evaluate the effects of PTSD polygenic risk (hit-1) and early life environmental insults (hit-2) on suicidal behavior in preadolescents. Notably, we were able to show a significant additive effect of the PTSD-PRS genetic effects on suicidality risk even after accounting for environmental stress, though the conditional effects were attenuated compared to the marginal effects, and were further attenuated when models included several environmental stressors. We suggest that future work using longitudinal data (soon to be released), which will include real-time data collection through wearable and mobile technologies, can clarify the role of proximal risk factors and triggers for suicidal behavior (hit-3). Additionally, future longitudinal analyses of ABCD data that will include more granular life events (e.g., data on bullying that has not yet been released) might reveal G X E or E X E effects that were not identified in the current analysis.

\subsection{Implications for suicide research}

Our findings have two main implications for suicide research, (1) supporting the use of cross-phenotype genetic risk to study childhood suicidality, and (2) supporting inclusion of non-European ancestries in assessment of genetic risk. Regarding clinical implications, while we are cautious in data interpretation, our findings can provide preliminary data informing potential future use of PRS for suicide risk stratification.
Notably, the PRS' effects on suicidality are relatively small compared to the large effect size of environmental stressors, (which were further reduced when including multiple environmental stressor in a single model), and were not statistically significant in the ancestry-specific analyses accounting for environmental stressors. However, PRS additive effects were statistically significant in the meta-analytic approach even when accounting for the environmental stressors, implying that the lack of statistical significance in each ancestry is likely due to underpowered sample size of both testing and training samples. Thus, our study provides a proof-of-concept supporting the approach of integrating genomic tools in suicide research modeling along with environmental exposures. Notably, the ultimate test for the utility of PRS addition to models that rely on environmental adversity will be when accounting for all environmental exposures in a single model, and then testing whether PRS adds to the explained variance. Still, the fact that we showed additive effects of PTSD-PRS to three different environmental adversities supports the concept that this approach may be useful as it does not depend on a specific stressor. Lastly, while the implications detailed above seem practical for next steps in suicide research, the very small effect size of the PRS provides further evidence that use of PRS alone is likely of low/no clinical utility. However, our findings suggesting additive effect of PRS on strong environmental suicide risk factors indicate that combining PRS with other risk factors might be 
Table 5

Additive effects of PTSD-PRS in explaining childhood suicidality when added to multiple environmental adversities in a single model.

\begin{tabular}{|c|c|c|c|c|c|c|}
\hline \multicolumn{7}{|c|}{ EUR participants $(\mathrm{N}=4619)$} \\
\hline & \multicolumn{3}{|c|}{ Model 1 (E effect) } & \multicolumn{3}{|c|}{$\begin{array}{l}\text { Model } 2 \text { (E effect + PTSD- } \\
\text { PRS (G)) }\end{array}$} \\
\hline & OR & $95 \% \mathrm{CI}$ & $\mathrm{p}$ & OR & $95 \%$ CI & $\mathrm{p}$ \\
\hline $\begin{array}{l}\text { Negative life events } \\
\text { (z-score) }\end{array}$ & 1.46 & $1.33-1.61$ & $<.001$ & 1.46 & $1.33-1.61$ & $<.001$ \\
\hline $\begin{array}{l}\text { Family conflict (z- } \\
\text { score) }\end{array}$ & 1.57 & $1.42-1.74$ & $<.001$ & 1.57 & $1.42-1.74$ & $<.001$ \\
\hline $\begin{array}{l}\text { LGBT } \\
\text { discrimination } \\
\text { (past year, } \\
\text { binary) }\end{array}$ & 3.99 & $2.71-5.86$ & $<.001$ & 3.98 & $2.71-5.85$ & $<.001$ \\
\hline PTSD-PRS & & & & 1.07 & $0.95-1.21$ & 0.264 \\
\hline Nagelkerke $\mathrm{R}^{2}$ & 0.133 & & & 0.133 & & \\
\hline \multicolumn{7}{|c|}{ AFR participants $(N=1334)$} \\
\hline & \multicolumn{3}{|c|}{ Model 1 (E effect) } & \multicolumn{3}{|c|}{$\begin{array}{l}\text { Model } 2 \text { (E effect + PTSD- } \\
\text { PRS (G)) }\end{array}$} \\
\hline & OR & $95 \% \mathrm{CI}$ & $\mathrm{p}$ & OR & $95 \% \mathrm{CI}$ & $\mathrm{p}$ \\
\hline $\begin{array}{l}\text { Negative life events } \\
\text { (z-score) }\end{array}$ & 1.6 & $1.34-1.9$ & $<.001$ & 1.6 & $1.34-1.91$ & $<.001$ \\
\hline $\begin{array}{l}\text { Family conflict (z- } \\
\text { score) }\end{array}$ & 1.27 & $1.05-1.54$ & 0.016 & 1.26 & $1.04-1.53$ & 0.017 \\
\hline $\begin{array}{l}\text { LGBT } \\
\text { discrimination } \\
\text { (past year, } \\
\text { binary) }\end{array}$ & 4.05 & $2.3-7.13$ & $<.001$ & 4.08 & $2.32-7.2$ & $<.001$ \\
\hline PTSD-PRS & \multirow{2}{*}{\multicolumn{3}{|c|}{0.116}} & 1.22 & $0.91-1.63$ & 0.178 \\
\hline Nagelkerke $\mathrm{R}^{2}$ & & & & 0.119 & & \\
\hline
\end{tabular}

Abbreviations: EUR = European ancestry; AFR = African Ancestry; E = Environment; $\mathrm{G}=$ genetic; $\mathrm{OR}=$ odds ratio; $\mathrm{CI}=$ confidence interval; $\mathrm{LGB}=$ Lesbian, gay, bisexual.

relevant for future risk stratification, as was recently suggested (Murray et al., 2021). More research is needed on how to leverage the powerful computational methodology behind PRS calculation and PRS from additional relevant phenotypes to inform clinical care and clinical decision making (Fullerton and Nurnberger, 2019).

\subsection{Limitations}

Limitations of this study include the use of AFR PRS based on AFR GWAS of PTSD, which was smaller and less well powered compared to the EUR GWAS of PTSD (Nievergelt et al., 2019). Future work is needed to expand AFR GWAS of PTSD for more well-powered AFR PRS estimates. Furthermore, we used a cross-PRS approach, with PTSD PRS predicting suicidality, rather than using a suicide attempt PRS (Mullins et al., 2019), which did not include AFR participants. Future studies based on diverse ancestry GWAS should attempt to test PRSs related to suicidal thoughts and behavior with suicidality outcomes in ABCD Study. In addition, we chose as an outcome of this study a phenotype that combined suicidal ideation and suicide attempt, which is consistent with prior work (Janiri et al., 2020), but is likely less accurate compared to defining separate suicidal phenotypes that probably have distinct biological underpinnings. This delineation to ideation versus attempt will require larger samples that are likely to be older. Lastly, we analyzed data collected at a single time point. As the ABCD study dataset grows, longitudinal analyses will be permitted and allow future work to investigate the predictive value of PTSD-PRS on studies evaluating genetic contribution to trajectories of suicidality over time.

\section{Conclusions}

In conclusion, our results support use of cross-phenotype PRS, specifically stress-susceptibility, as a genetic marker for risk of suicidality early in life. These data further demonstrate that stress-susceptibility PRS are markers for suicidality across ancestry groups. Future studies leveraging the longitudinal data expected to be released from the ABCD Study could evaluate causal relationships and the generalizability of the effects to older subjects, as well as study sex differences that are likely to emerge as the study population enters into mid- and late-adolescence.

\section{Funding}

This study was supported by the National Institute of Mental Health grants R21MH121909 (NPD), K23MH120437 (RB), R21MH123916 (RB), RO1MH117014 (TMM) and the Lifespan Brain Institute of Children's Hospital of Philadelphia and Penn Medicine, University of Pennsylvania.

\section{Role of the funding source}

The funding organizations had no role in the design and conduct of the study; collection, management, analysis, and interpretation of the data; preparation, review, or approval of the manuscript; and decision to submit the manuscript for publication.

\section{CRediT authorship contribution statement}

Nikolaos P. Daskalakis: Conceptualization, Investigation, Methodology, Supervision, Funding acquisition, Writing - original draft, Writing - review \& editing. Laura M. Schultz: Data curation, Formal analysis, Investigation, Methodology, Software, Visualization, Writing review \& editing. Elina Visoki: Data curation, Formal analysis, Methodology, Software, Writing - review \& editing. Tyler M. Moore: Formal analysis, Investigation, Methodology, Supervision, Funding acquisition, Writing - review \& editing. Stirling T. Argabright: Data curation, Formal analysis, Writing - review \& editing. Nathaniel G. Harnett: Conceptualization, Investigation, Writing - review \& editing. Grace E. DiDomenico: Data curation, Project administration, Writing - review \& editing. Varun Warrier: Formal analysis, Investigation, Methodology, Writing - review \& editing. Laura Almasy: Conceptualization, Investigation, Methodology, Supervision, Writing - review \& editing. Ran Barzilay: Conceptualization, Formal analysis, Investigation, Methodology, Supervision, Funding acquisition, Writing - original draft, Writing review \& editing.

\section{Data availability}

This analysis uses data from the ABCD Study that can be made available to researchers through the NIH NDA.

\section{Acknowledgement}

Data used in the preparation of this article were obtained from the Adolescent Brain Cognitive Development ${ }^{\mathrm{SM}}$ (ABCD) Study (https://abcd study.org), held in the NIMH Data Archive (NDA). This is a multisite, longitudinal study designed to recruit more than 10,000 children age 9-10 and follow them over 10 years into early adulthood. The ABCD Study ${ }^{\circledR}$ is supported by the National Institutes of Health and additional federal partners under award numbers U01DA041048, U01DA050989, U01DA051016, U01DA041022, U01DA051018, U01DA051037, U01DA050987, U01DA041174, U01DA041106, U01DA041117, U01DA041028, U01DA041134, U01DA050988, U01DA051039, U01DA041156, U01DA041025, U01DA041120, U01DA051038, U01DA041148, U01DA041093, U01DA041089, U24DA041123, U24DA041147. A full list of supporters is available at https://abcdstudy. org/federal-partners.html. A listing of participating sites and a complete listing of the study investigators can be found at https://abcdstudy.org/ consortium_members/. ABCD consortium investigators designed and implemented the study and/or provided data but did not necessarily 
participate in analysis or writing of this report. This manuscript reflects the views of the authors and may not reflect the opinions or views of the $\mathrm{NIH}$ or ABCD consortium investigators.

\section{Appendix A. Supplementary data}

Supplementary data to this article can be found online at https://doi. org/10.1016/j.ynstr.2021.100411.

\section{Declaration of interest statement}

In the past 3 years, NPD has held a part-time paid position at Cohen Veterans Bioscience, has been a consultant for Sunovion Pharmaceuticals and is on the scientific advisory board for Sentio Solutions for unrelated work. RB serves on the scientific board and reports stock ownership in 'Taliaz Health', with no conflict of interest relevant to this work. All other authors have no conflicts of interest to disclose.

\section{References}

Almeida, J., Johnson, R.M., Corliss, H.L., Molnar, B.E., Azrael, D., 2009. Emotional distress among LGBT youth: the influence of perceived discrimination based on sexual orientation. J. Youth Adolesc. 38, 1001-1014.

Bigdeli, T.B., Fanous, A.H., Li, Y., Rajeevan, N., Sayward, F., Genovese, G., Gupta, R., Radhakrishnan, K., Malhotra, A.K., Sun, N., Lu, Q., Hu, Y., Li, B., Chen, Q., Mane, S., Miller, P., Cheung, K.H., Gur, R.E., Greenwood, T.A., Braff, D.L., Achtyes, E.D., Buckley, P.F., Escamilla, M.A., Lehrer, D., Malaspina, D.P., McCarroll, S.A., Rapaport, M.H., Vawter, M.P., Pato, M.T., Pato, C.N., Zhao, H., Kosten, T.R., Brophy, M., Pyarajan, S., Shi, Y., O’Leary, T.J., Gleason, T., Przygodzki, R., Muralidhar, S., Gaziano, J.M., Million Veteran, P., Huang, G.D., Concato, J., Siever, L.J., Aslan, M., Harvey, P.D., Consortium on the Genetics of, S., Genomic Psychiatry Cohort, I., 2021. Genome-wide association studies of schizophrenia and bipolar disorder in a diverse cohort of US veterans. Schizophr. Bull. 47 (2).

Bridge, J.A., Horowitz, L.M., Fontanella, C.A., Sheftall, A.H., Greenhouse, J., Kelleher, K. J., Campo, J.V., 2018. Age-related racial disparity in suicide rates among US youths from 2001 through 2015. JAMA Pediatr 172, 697-699.

Cash, S.J., Bridge, J.A., 2009. Epidemiology of youth suicide and suicidal behavior. Curr. Opin. Pediatr. 21, 613-619.

Centers for Disease Control and Prevention, 2021. WISQARS Leading Causes of Death Reports, National and Regional. In: S S, N.V. (Ed.), National Center for Health Statistics, 2008-2018.

Chang, C.C., Chow, C.C., Tellier, L.C., Vattikuti, S., Purcell, S.M., Lee, J.J., 2015. Secondgeneration PLINK: rising to the challenge of larger and richer datasets. GigaScience 4,7 .

Chatzinakos, C., Georgiadis, F., Lee, D., Cai, N., Vladimirov, V.I., Docherty, A., Webb, B. T., Riley, B.P., Flint, J., Kendler, K.S., Daskalakis, N.P., Bacanu, S.A., 2020. TWAS pathway method greatly enhances the number of leads for uncovering the molecular underpinnings of psychiatric disorders. Am J Med Genet B Neuropsychiatr Genet 183, 454-463.

Copeland, W.E., Goldston, D.B., Costello, E.J., 2017. Adult associations of childhood suicidal thoughts and behaviors: a prospective, longitudinal analysis. J. Am. Acad. Child Adolesc. Psychiatry 56, 958-965 e954.

Crouch, D.J.M., Bodmer, W.F., 2020. Polygenic inheritance, GWAS, polygenic risk scores, and the search for functional variants. Proc. Natl. Acad. Sci. U. S. A. 117, 18924-18933.

Das, S., Forer, L., Schonherr, S., Sidore, C., Locke, A.E., Kwong, A., Vrieze, S.I., Chew, E. Y., Levy, S., McGue, M., Schlessinger, D., Stambolian, D., Loh, P.R., Iacono, W.G., Swaroop, A., Scott, L.J., Cucca, F., Kronenberg, F., Boehnke, M., Abecasis, G.R., Fuchsberger, C., 2016. Next-generation genotype imputation service and methods. Nat. Genet. 48, 1284-1287.

Daskalakis, N.P., Bagot, R.C., Parker, K.J., Vinkers, C.H., de Kloet, E.R., 2013. The threehit concept of vulnerability and resilience: toward understanding adaptation to early-life adversity outcome. Psychoneuroendocrinology 38, 1858-1873.

Duncan, L., Shen, H., Gelaye, B., Meijsen, J., Ressler, K., Feldman, M., Peterson, R., Domingue, B., 2019. Analysis of polygenic risk score usage and performance in diverse human populations. Nat. Commun. 10, 3328.

Fazel, S., Runeson, B., 2020. Suicide. N. Engl. J. Med. 382, 266-274.

Fullerton, J.M., Nurnberger, J.I., 2019. Polygenic risk scores in psychiatry: will they be useful for clinicians? F1000Res 8.

Garavan, H., Bartsch, H., Conway, K., Decastro, A., Goldstein, R.Z., Heeringa, S., Jernigan, T., Potter, A., Thompson, W., Zahs, D., 2018. Recruiting the ABCD sample: design considerations and procedures. Dev Cogn Neurosci 32, 16-22.

Ge, T., Chen, C.Y., Ni, Y., Feng, Y.A., Smoller, J.W., 2019. Polygenic prediction via Bayesian regression and continuous shrinkage priors. Nat. Commun. 10, 1776.

Gelernter, J., Sun, N., Polimanti, R., Pietrzak, R., Levey, D.F., Bryois, J., Lu, Q., Hu, Y., Li, B., Radhakrishnan, K., Aslan, M., Cheung, K.H., Li, Y., Rajeevan, N., Sayward, F. Harrington, K., Chen, Q., Cho, K., Pyarajan, S., Sullivan, P.F., Quaden, R., Shi, Y., Hunter-Zinck, H., Gaziano, J.M., Concato, J., Zhao, H., Stein, M.B., , Department of Veterans Affairs Cooperative Studies, P, Million Veteran, P., 2019. Genome-wide association study of post-traumatic stress disorder reexperiencing symptoms in $>165,000$ US veterans. Nat. Neurosci. 22, 1394-1401.

Girgenti, M.J., Wang, J., Ji, D., Cruz, D.A., , Traumatic Stress Brain Research, G., Stein, M.B., Gelernter, J., Young, K.A., Huber, B.R., Williamson, D.E., Friedman, M. J., Krystal, J.H., Zhao, H., Duman, R.S., 2021. Transcriptomic organization of the human brain in post-traumatic stress disorder. Nat. Neurosci. 24, 24-33.

Herba, C.M., Ferdinand, R.F., van der Ende, J., Verhulst, F.C., 2007. Long-term associations of childhood suicide ideation. J. Am. Acad. Child Adolesc. Psychiatry 46, 1473-1481.

Hoffman, E.A., Clark, D.B., Orendain, N., Hudziak, J., Squeglia, L.M., Dowling, G.J., 2019. Stress exposures, neurodevelopment and health measures in the ABCD study. Neurobiol Stress 10, 100157.

Huckins, L.M., Chatzinakos, C., Breen, M.S., Hartmann, J., Klengel, T., da Silva Almeida, A.C., Dobbyn, A., Girdhar, K., Hoffman, G.E., Klengel, C., Logue, M.W., Lori, A., Maihofer, A.X., Morrison, F.G., Nguyen, H.T., Park, Y., Ruderfer, D., Sloofman, L.G., van Rooij, S.J.H., Consortium, P.W., Baker, D.G., Chen, C.Y., Cox, N., Duncan, L.E., Geyer, M.A., Glatt, S.J., Im, H.K., Risbrough, V.B., Smoller, J.W., Stein, D.J., Yehuda, R., Liberzon, I., Koenen, K.C., Jovanovic, T., Kellis, M., Miller, M.W., Bacanu, S.A., Nievergelt, C.M., Buxbaum, J.D., Sklar, P., Ressler, K.J., Stahl, E.A., Daskalakis, N.P., 2020. Analysis of genetically regulated gene expression identifies a prefrontal PTSD gene, SNRNP35, specific to military cohorts. Cell Rep. 31, 107716.

Janiri, D., Doucet, G.E., Pompili, M., Sani, G., Luna, B., Brent, D.A., Frangou, S., 2020. Risk and protective factors for childhood suicidality: a US population-based study. Lancet Psychiat 7, 317-326.

Kaufman, J., Birmaher, B., Brent, D., Rao, U., Flynn, C., Moreci, P., Williamson, D., Ryan, N., 1997. Schedule for affective disorders and schizophrenia for school-age children-present and lifetime version (K-SADS-PL): initial reliability and validity data. J. Am. Acad. Child Adolesc. Psychiatry 36, 980-988.

Laursen, T.M., Trabjerg, B.B., Mors, O., Borglum, A.D., Hougaard, D.M., Mattheisen, M., Meier, S.M., Byrne, E.M., Mortensen, P.B., Munk-Olsen, T., Agerbo, E., 2017. Association of the polygenic risk score for schizophrenia with mortality and suicidal behavior - a Danish population-based study. Schizophr. Res. 184, 122-127.

Lindsey, M.A., Sheftall, A.H., Xiao, Y., Joe, S., 2019. Trends of suicidal behaviors among high school students in the United States: 1991-2017. Pediatrics 144, e20191187.

Manichaikul, A., Mychaleckyj, J.C., Rich, S.S., Daly, K., Sale, M., Chen, W.M., 2010. Robust relationship inference in genome-wide association studies. Bioinformatics 26, 2867-2873.

Marouli, E., Graff, M., Medina-Gomez, C., Lo, K.S., Wood, A.R., Kjaer, T.R., Fine, R.S., Lu, Y., Schurmann, C., Highland, H.M., Rueger, S., Thorleifsson, G., Justice, A.E., Lamparter, D., Stirrups, K.E., Turcot, V., Young, K.L., Winkler, T.W., Esko, T. Karaderi, T., Locke, A.E., Masca, N.G., Ng, M.C., Mudgal, P., Rivas, M.A., Vedantam, S., Mahajan, A., Guo, X., Abecasis, G., Aben, K.K., Adair, L.S., Alam, D.S., Albrecht, E., Allin, K.H., Allison, M., Amouyel, P., Appel, E.V., Arveiler, D. Asselbergs, F.W., Auer, P.L., Balkau, B., Banas, B., Bang, L.E., Benn, M., Bergmann, S., Bielak, L.F., Bluher, M., Boeing, H., Boerwinkle, E., Boger, C.A. Bonnycastle, L.L., Bork-Jensen, J., Bots, M.L., Bottinger, E.P., Bowden, D.W., Brandslund, I., Breen, G., Brilliant, M.H., Broer, L., Burt, A.A., Butterworth, A.S., Carey, D.J., Caulfield, M.J., Chambers, J.C., Chasman, D.I., Chen, Y.I., Chowdhury, R., Christensen, C., Chu, A.Y., Cocca, M., Collins, F.S., Cook, J.P., Corley, J., Galbany, J.C., Cox, A.J., Cuellar-Partida, G., Danesh, J., Davies, G., de Bakker, P.I., de Borst, G.J., de Denus, S., de Groot, M.C., de Mutsert, R., Deary, I.J., Dedoussis, G., Demerath, E.W., den Hollander, A.I., Dennis, J.G., Di Angelantonio, E., Drenos, F., Du, M., Dunning, A.M., Easton, D.F., Ebeling, T., Edwards, T.L., Ellinor, P.T., Elliott, P., Evangelou, E., Farmaki, A.E., Faul, J.D., Feitosa, M.F., Feng, S., Ferrannini, E., Ferrario, M.M., Ferrieres, J., Florez, J.C., Ford, I., Fornage, M., Franks, P.W., Frikke-Schmidt, R., Galesloot, T.E., Gan, W., Gandin, I., Gasparini, P., Giedraitis, V., Giri, A., Girotto, G., Gordon, S.D., GordonLarsen, P., Gorski, M., Grarup, N., Grove, M.L., Gudnason, V., Gustafsson, S., Hansen, T., Harris, K.M., Harris, T.B., Hattersley, A.T., Hayward, C., He, L., Heid, I. M., Heikkila, K., Helgeland, O., Hernesniemi, J., Hewitt, A.W., Hocking, L.J., Hollensted, M., Holmen, O.L., Hovingh, G.K., Howson, J.M., Hoyng, C.B., Huang, P. L., Hveem, K., Ikram, M.A., Ingelsson, E., Jackson, A.U., Jansson, J.H., Jarvik, G.P., Jensen, G.B., Jhun, M.A., Jia, Y., Jiang, X., Johansson, S., Jorgensen, M.E., Jorgensen, T., Jousilahti, P., Jukema, J.W., Kahali, B., Kahn, R.S., Kahonen, M., Kamstrup, P.R., Kanoni, S., Kaprio, J., Karaleftheri, M., Kardia, S.L., Karpe, F., Kee, F., Keeman, R., Kiemeney, L.A., Kitajima, H., Kluivers, K.B., Kocher, T., Komulainen, P., Kontto, J., Kooner, J.S., Kooperberg, C., Kovacs, P., Kriebel, J., Kuivaniemi, H., Kury, S., Kuusisto, J., La Bianca, M., Laakso, M., Lakka, T.A., Lange, E.M., Lange, L.A., Langefeld, C.D., Langenberg, C., Larson, E.B., Lee, I.T., Lehtimaki, T., Lewis, C.E., Li, H., Li, J., Li-Gao, R., Lin, H., Lin, L.A., Lin, X., Lind, L., Lindstrom, J., Linneberg, A., Liu, Y., Liu, Y., Lophatananon, A., Luan, J., Lubitz, S.A., Lyytikainen, L.P., Mackey, D.A., Madden, P.A., Manning, A.K., Mannisto, S., Marenne, G., Marten, J., Martin, N.G., Mazul, A.L., Meidtner, K., Metspalu, A., Mitchell, P., Mohlke, K.L., Mook-Kanamori, D.O., Morgan, A., Morris, A.D., Morris, A.P., Muller-Nurasyid, M., Munroe, P.B., Nalls, M.A., Nauck, M., Nelson, C. P., Neville, M., Nielsen, S.F., Nikus, K., Njolstad, P.R., Nordestgaard, B.G., Ntalla, I., O'Connel, J.R., Oksa, H., Loohuis, L.M., Ophoff, R.A., Owen, K.R., Packard, C.J., Padmanabhan, S., Palmer, C.N., Pasterkamp, G., Patel, A.P., Pattie, A., Pedersen, O., Peissig, P.L., Peloso, G.M., Pennell, C.E., Perola, M., Perry, J.A., Perry, J.R., Person, T.N., Pirie, A., Polasek, O., Posthuma, D., Raitakari, O.T., Rasheed, A., Rauramaa, R., Reilly, D.F., Reiner, A.P., Renstrom, F., Ridker, P.M., Rioux, J.D., Robertson, N., Robino, A., Rolandsson, O., Rudan, I., Ruth, K.S., Saleheen, D. Salomaa, V., Samani, N.J., Sandow, K., Sapkota, Y., Sattar, N., Schmidt, M.K., Schreiner, P.J., Schulze, M.B., Scott, R.A., Segura-Lepe, M.P., Shah, S., Sim, X., Sivapalaratnam, S., Small, K.S., Smith, A.V., Smith, J.A., Southam, L., Spector, T.D., 
Speliotes, E.K., Starr, J.M., Steinthorsdottir, V., Stringham, H.M., Stumvoll, M., Surendran, P., tHart, L.M., Tansey, K.E., Tardif, J.C., Taylor, K.D., Teumer, A., Thompson, D.J., Thorsteinsdottir, U., Thuesen, B.H., Tonjes, A., Tromp, G., Trompet, S., Tsafantakis, E., Tuomilehto, J., Tybjaerg-Hansen, A., Tyrer, J.P., Uher, R., Uitterlinden, A.G., Ulivi, S., van der Laan, S.W., Van Der Leij, A.R., van Duijn, C.M., van Schoor, N.M., van Setten, J., Varbo, A., Varga, T.V., Varma, R., Edwards, D.R., Vermeulen, S.H., Vestergaard, H., Vitart, V., Vogt, T.F., Vozzi, D., Walker, M., Wang, F., Wang, C.A., Wang, S., Wang, Y., Wareham, N.J., Warren, H.R., Wessel, J., Willems, S.M., Wilson, J.G., Witte, D.R., Woods, M.O., Wu, Y., Yaghootkar, H., Yao, J., Yao, P., Yerges-Armstrong, L.M., Young, R., Zeggini, E., Zhan, X., Zhang, W., Zhao, J.H., Zhao, W., Zhao, W., Zheng, H., Zhou, W., Consortium, E.P.-I., Consortium, C.H.D.E., Exome, B.P.C., Consortium, T.D.-G., Go, T.D.G.C., , Global Lipids Genetics, C., ReproGen, C., Investigators, M., Rotter, J. I., Boehnke, M., Kathiresan, S., McCarthy, M.I., Willer, C.J., Stefansson, K., Borecki, I.B., Liu, D.J., North, K.E., Heard-Costa, N.L., Pers, T.H., Lindgren, C.M., Oxvig, C., Kutalik, Z., Rivadeneira, F., Loos, R.J., Frayling, T.M., Hirschhorn, J.N., Deloukas, P., Lettre, G., 2017. Rare and low-frequency coding variants alter human adult height. Nature 542, 186-190.

Martin, A.R., Kanai, M., Kamatani, Y., Okada, Y., Neale, B.M., Daly, M.J., 2019. Clinical use of current polygenic risk scores may exacerbate health disparities. Nat. Genet. 51, 584-591.

Meyer, D., Dimitriadou, E., Hornik, K., Weingessel, A., Leisch, F., Chang, C.-C., Lin, C.-C., 2020. Misc Functions of the Department of Statistics, Probability Theory Group (Formerly: E1071), vol. 1. TU Wien, 7-3. https://CRAN.R-project.org/p ackage=e1071.

Mishara, B.L., Stijelja, S., 2020. Trends in US suicide deaths, 1999 to 2017, in the context of suicide prevention legislation. JAMA Pediatr 174, 499-500.

Mullins, N., Bigdeli, T.B., Borglum, A.D., Coleman, J.R.I., Demontis, D., Mehta, D., Power, R.A., Ripke, S., Stahl, E.A., Starnawska, A., Anjorin, A., Psych, M.R.C., Corvin, A., Sanders, A.R., Forstner, A.J., Reif, A., Koller, A.C., Swiatkowska, B., Baune, B.T., Muller-Myhsok, B., Penninx, B., Pato, C., Zai, C., Rujescu, D., Hougaard, D.M., Quested, D., Levinson, D.F., Binder, E.B., Byrne, E.M., Agerbo, E., Sc, Dr.Med., Streit, F., Mayoral, F., Bellivier, F., Degenhardt, F., Breen, G., Morken, G., Turecki, G., Rouleau, G.A., Grabe, H.J., Volzke, H., Jones, I., Giegling, I., Agartz, I., Melle, I., Lawrence, J., Psych, M.R.C., Walters, J.T.R., Strohmaier, J., Shi, J., Hauser, J., Biernacka, J.M., Vincent, J.B., Kelsoe, J., Strauss, J.S., Lissowska, J., Pimm, J., Psych, M.R.C., Smoller, J.W., Guzman-Parra, J., Berger, K. Scott, L.J., Jones, L.A., Azevedo, M.H., Trzaskowski, M., Kogevinas, M., Rietschel, M., Boks, M., Ising, M., Grigoroiu-Serbanescu, M., Hamshere, M.L., Leboyer, M., Frye, M., Nothen, M.M., Alda, M., Preisig, M., Nordentoft, M., Boehnke, M., O’Donovan, M.C., Owen, M.J., Pato, M.T., Renteria, M.E., Budde, M., Dipl, P., Weissman, M.M., Wray, N.R., Bass, N., Psych, M.R.C., Craddock, N., Smeland, O.B., Andreassen, O.A., Mors, O., Gejman, P.V., Sklar, P., McGrath, P., Hoffmann, P., McGuffin, P., Lee, P.H., Mortensen, P.B., Kahn, R.S., Ophoff, R.A., Adolfsson, R., Van der Auwera, S., Djurovic, S., Kloiber, S., Heilmann-Heimbach, S., Jamain, S., Hamilton, S.P., McElroy, S.L., Lucae, S., Cichon, S., Schulze, T.G., Hansen, T., Werge, T., Air, T.M., Nimgaonkar, V., Appadurai, V., Cahn, W., Milaneschi, Y., , Major Depressive Disorder Working Group of the Psychiatric Genomics, C., Bipolar Disorder Working Group of the Psychiatric Genomics, C., Schizophrenia Working Group of the Psychiatric Genomics, C., Fanous, A.H., Kendler, K.S., McQuillin, A., Lewis, C.M., 2019. GWAS of suicide attempt in psychiatric disorders and association with major depression polygenic risk scores. Am. J. Psychiatr. 176, 651-660.

Murray, G.K., Lin, T., Austin, J., McGrath, J.J., Hickie, I.B., Wray, N.R., 2021. Could polygenic risk scores Be useful in psychiatry?: a review. JAMA Psychiatry 78, 210-219.

Naghavi, M., Global Burden of Disease Self-Harm, 2019. Global, regional, and national burden of suicide mortality 1990 to 2016: systematic analysis for the Global Burden of Disease Study 2016. C. BMJ 364, 194.

Nievergelt, C.M., Maihofer, A.X., Klengel, T., Atkinson, E.G., Chen, C.Y., Choi, K.W., Coleman, J.R.I., Dalvie, S., Duncan, L.E., Gelernter, J., Levey, D.F., Logue, M.W., Polimanti, R., Provost, A.C., Ratanatharathorn, A., Stein, M.B., Torres, K., Aiello, A. E., Almli, L.M., Amstadter, A.B., Andersen, S.B., Andreassen, O.A., Arbisi, P.A., Ashley-Koch, A.E., Austin, S.B., Avdibegovic, E., Babic, D., Baekvad-Hansen, M., Baker, D.G., Beckham, J.C., Bierut, L.J., Bisson, J.I., Boks, M.P., Bolger, E.A., Borglum, A.D., Bradley, B., Brashear, M., Breen, G., Bryant, R.A., Bustamante, A.C.,
Bybjerg-Grauholm, J., Calabrese, J.R., Caldas-de-Almeida, J.M., Dale, A.M., Daly, M. J., Daskalakis, N.P., Deckert, J., Delahanty, D.L., Dennis, M.F., Disner, S.G., Domschke, K., Dzubur-Kulenovic, A., Erbes, C.R., Evans, A., Farrer, L.A., Feeny, N.C., Flory, J.D., Forbes, D., Franz, C.E., Galea, S., Garrett, M.E., Gelaye, B., Geuze, E., Gillespie, C., Uka, A.G., Gordon, S.D., Guffanti, G., Hammamieh, R., Harnal, S., Hauser, M.A., Heath, A.C., Hemmings, S.M.J., Hougaard, D.M., Jakovljevic, M., Jett, M., Johnson, E.O., Jones, I., Jovanovic, T., Qin, X.J., Junglen, A.G., Karstoft, K. I., Kaufman, M.L., Kessler, R.C., Khan, A., Kimbrel, N.A., King, A.P., Koen, N., Kranzler, H.R., Kremen, W.S., Lawford, B.R., Lebois, L.A.M., Lewis, C.E., Linnstaedt, S.D., Lori, A., Lugonja, B., Luykx, J.J., Lyons, M.J., Maples-Keller, J., Marmar, C., Martin, A.R., Martin, N.G., Maurer, D., Mavissakalian, M.R., McFarlane, A., McGlinchey, R.E., McLaughlin, K.A., McLean, S.A., McLeay, S., Mehta, D., Milberg, W.P., Miller, M.W., Morey, R.A., Morris, C.P., Mors, O., Mortensen, P.B., Neale, B.M., Nelson, E.C., Nordentoft, M., Norman, S.B., O'Donnell, M., Orcutt, H.K., Panizzon, M.S., Peters, E.S., Peterson, A.L., Peverill, M., Pietrzak, R.H., Polusny, M.A., Rice, J.P., Ripke, S., Risbrough, V.B., Roberts, A.L., Rothbaum, A.O., Rothbaum, B.O., Roy-Byrne, P., Ruggiero, K., Rung, A., Rutten, B.P. F., Saccone, N.L., Sanchez, S.E., Schijven, D., Seedat, S., Seligowski, A.V., Seng, J.S., Sheerin, C.M., Silove, D., Smith, A.K., Smoller, J.W., Sponheim, S.R., Stein, D.J., Stevens, J.S., Sumner, J.A., Teicher, M.H., Thompson, W.K., Trapido, E., Uddin, M., Ursano, R.J., van den Heuvel, L.L., Van Hooff, M., Vermetten, E., Vinkers, C.H., Voisey, J., Wang, Y., Wang, Z., Werge, T., Williams, M.A., Williamson, D.E., Winternitz, S., Wolf, C., Wolf, E.J., Wolff, J.D., Yehuda, R., Young, R.M., Young, K. A., Zhao, H., Zoellner, L.A., Liberzon, I., Ressler, K.J., Haas, M., Koenen, K.C., 2019. International meta-analysis of PTSD genome-wide association studies identifies sexand ancestry-specific genetic risk loci. Nat. Commun. 10, 4558.

Plemmons, G., Hall, M., Doupnik, S., Gay, J., Brown, C., Browning, W., Casey, R., Freundlich, K., Johnson, D.P., Lind, C., Rehm, K., Thomas, S., Williams, D., 2018. Hospitalization for Suicide Ideation or Attempt: 2008-2015. Pediatrics vol. 141, e20172426.

Price, J.H., Khubchandani, J., 2019. The changing characteristics of african-American adolescent suicides, 2001-2017. J. Community Health 44, 756-763.

R Core Team, 2019. R: A Language and Environment for Statistical Computing. R Foundation for Statistical Computing, Vienna, Austria.

Ruch, D.A., Sheftall, A.H., Schlagbaum, P., Rausch, J., Campo, J.V., Bridge, J.A., 2019. Trends in suicide among youth aged 10 to 19 Years in the United States, 1975 to 2016. JAMA Netw Open 2, e193886.

Serafini, G., Muzio, C., Piccinini, G., Flouri, E., Ferrigno, G., Pompili, M., Girardi, P., Amore, M., 2015. Life adversities and suicidal behavior in young individuals: a systematic review. Eur. Child Adolesc. Psychiatr. 24, 1423-1446.

Shen, X., Howard, D.M., Adams, M.J., Hill, W.D., Clarke, T.K., , Major Depressive Disorder Working Group of the Psychiatric Genomics, Deary, I.J., Whalley, H.C., McIntosh, A.M., 2020. A phenome-wide association and Mendelian Randomisation study of polygenic risk for depression in UK Biobank. C. Nat. Commun. 11, 2301.

Slopen, N., Shonkoff, J.P., Albert, M.A., Yoshikawa, H., Jacobs, A., Stoltz, R., Williams, D.R., 2016. Racial disparities in child adversity in the U.S.: interactions with family immigration history and income. Am. J. Prev. Med. 50, 47-56.

Stein, M.B., Levey, D.F., Cheng, Z., Wendt, F.R., Harrington, K., Pathak, G.A., Cho, K., Quaden, R., Radhakrishnan, K., Girgenti, M.J., Ho, Y.A., Posner, D., Aslan, M., Duman, R.S., Zhao, H., , Department of Veterans Affairs Cooperative Studies, P, Program, V.A.M.V., Polimanti, R., Concato, J., Gelernter, J., 2021. Genome-wide association analyses of post-traumatic stress disorder and its symptom subdomains in the Million Veteran Program. Nat. Genet. 53, 174-184.

Turecki, G., Brent, D.A., 2016. Suicide and suicidal behaviour. Lancet 387, 1227-1239.

Turecki, G., Brent, D.A., Gunnell, D., O'Connor, R.C., Oquendo, M.A., Pirkis, J., Stanley, B.H., 2019. Suicide and suicide risk. Nat Rev Dis Primers 5, 74.

Uban, K.A., Horton, M.K., Jacobus, J., Heyser, C., Thompson, W.K., Tapert, S.F., Madden, P.A.F., Sowell, E.R., Adolescent Brain Cognitive Development, S, 2018. Biospecimens and the ABCD study: rationale, methods of collection, measurement and early data. Dev Cogn Neurosci 32, 97-106.

Warrier, V., Baron-Cohen, S., 2019. Childhood trauma, life-time self-harm, and suicidal behaviour and ideation are associated with polygenic scores for autism. Mol. Psychiatr.

Yu, B., Chen, X., 2019. Age and birth cohort-adjusted rates of suicide mortality among US male and female youths aged 10 to 19 Years from 1999 to 2017. JAMA Netw Open 2, e1911383. 